\title{
Determination of the optimal air-fuel ratio for upgraded biogas engine operation
}

\author{
Radostin Dimitrov ${ }^{1, *}$, and Penka Zlateva ${ }^{2}$ \\ ${ }^{1}$ Technical University of Varna, Department Transport Engineering and Technologies, 1 Studentska \\ Str., 9010 Varna, Bulgaria \\ ${ }^{2}$ Technical University of Varna, Department of Thermal Engineering,1 Studentska Str., 9010 Varna, \\ Bulgaria
}

\begin{abstract}
The paper reveals a study about air-fuel ratio variation of sparkignition engine running on upgraded biogas (biomethane). Using biogas as internal combustion engine fuel and external mixture formation is a new approach to decrease harmful exhaust gas emissions. To obtain minimum concentrations of exhaust gases harmful emissions the engine must work with optimal air-fuel ratio. This research contains analysis of many test engine adjusting characteristics to determine optimal air-fuel ratio for each working regime and to obtain maximum effective working process by the use of biomethane as a fuel. Three-dimensional graphics of air-fuel ratio variation across the rpm and load range were made. In conclusion based on performed experiments, a table with values of air-fuel ratio for all engine operating modes and dependence on rpm and load of the engine is proposed.
\end{abstract}

\section{Introduction}

The ever-increasing environmental requirements and regulations for exhaust gas determined by European legislation dictate the growing use of alternative fuel sources [1-3]. Using alternative fuels is one of the most feasible options to reduce $\mathrm{CO}_{2}$ emissions is by using alternative fuels. For Spark-Ignition engines, these alternative fuels can be: LPG (liquid petroleum gas), CNG (compressed natural gas), different types of alcohols and biogas [4].

The new method for decreasing exhaust gas emission involves the use of biogas. Biogas is alternative fuel derived from Renewable Energy Sources, containing basically methane and carbon dioxide. Its composition depends on the type of raw material used for its production [5]. The methane concentration in biogas is between 50 and $80 \%$ [6]. The biogas obtained needs to be further purified in order to be used as fuel for internal combustion engines [7].

The resultant mixture is composed mainly of methane and is called biomethane. To enable an engine to operate with maximum efficiency, it is necessary to determine the optimal ratio of mixture of biomethane and air entering into the cylinder [8].

As an alternative fuel, biomethane is of growing interest due to its lowest exhaust gas emissions when burnt in the engine [9]. The fuel systems developed for methane operation

\footnotetext{
*Corresponding author: r_dimitrov@tu-varna.bg
} 
are characterized by the additional large weight of the fuel tank and the lower power output upon engine retrofitting, which are advantages to be taken into account. On the other hand, this fuel has better environmental performance and low cost, which justifies the tendency toward its use [10-13].

Since the different nature of methane as a fuel, it requires a greater quantity of air for achieving its complete combustion. Thus, $17.19 \mathrm{~kg}$ air is necessary to burn $1 \mathrm{~kg}$ biomethane as compared to the amount of air required for the engine when running on conventional gasoline fuel, i.e. $14.7 \mathrm{~kg}$ air for burning $1 \mathrm{~kg}$ gasoline. These factors dictate the need for the determination of air-fuel ratio for each operating mode of the engine when using methane as a fuel [14-17].

This study aims at establishing the optimal air-fuel ratio for achieving the highest efficiency of the engine operation working on biomethane over the whole speed and load range of operation.

\section{Experimental methodology}

Table 1 shows the parameters of the Spark-Ignition engine used for conducting the experiments included in the study:

Table 1. Test engine parameters.

\begin{tabular}{|c|l|c|}
\hline № & \multicolumn{1}{|c|}{ Parameter } & Value \\
\hline 1 & Volume $\left[\mathrm{dm}^{3}\right]$ & 1.275 \\
\hline 2 & Cylinder diameter $[\mathrm{mm}]$ & 70.61 \\
\hline 3 & Stroke $[\mathrm{mm}]$ & 81.28 \\
\hline 4 & Compression ratio & 9.75 \\
\hline 5 & Nominal power/ crankshaft speed $\left[\mathrm{kW} / \mathrm{min}^{-1}\right]$ & $46 / 5500$ \\
\hline 6 & Nominal torque/ crankshaft speed $\left[\mathrm{Nm} / \mathrm{min}^{-1}\right]$ & $95 / 3000$ \\
\hline
\end{tabular}

The Biomethane fuel system is conventionally equipped with a reducer-evaporator, which facilitates the adjustment of the air-fuel ratio of the mixture. The engine is connected to an electric DC current dynamometer. The multitude characteristics established for the air-fuel adjustment parameters are employed to find the optimal parameters promoting the highest efficiency of the combustion process. Also, for each point of measurements, an indicator diagram was drawn using a piezo-quartz sensor of the Kistler brand.

A schematic diagram of the laboratory unit is shown in Fig. 1, where: 


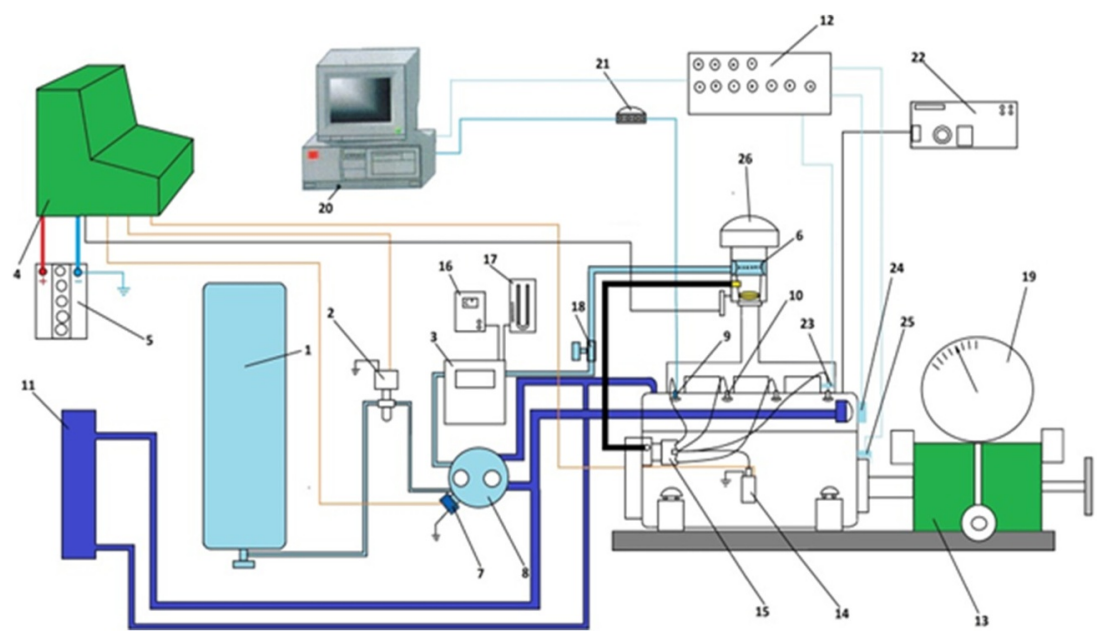

Fig. 1. Experimental apparatus.

1 - biomethane bottle;

4-control panel;

7 - stop magnetic valve;

10 - spark plugs;

13 - dynamometer;

16 - thermometer;

19 - brake force scale;

22 - gas analyzer;

25 - hall effect sensor;
2 - magnetic valve;

5 - battery;

8 - reducer-evaporator;

11 - cooling engine system;

14 - ignition coil;

17 - pressure gauge;

20 - PC system;

23 - ignition system sensor;

26 - air filter.

$$
\begin{aligned}
& 3 \text { - flow meter; } \\
& 6 \text { - mixer; } \\
& 9 \text { - pressure sensor; } \\
& 12 \text { - BNC adapter; } \\
& 15 \text { - distributor; } \\
& 18 \text { - gas regulator; } \\
& 21 \text { - amplifier; } \\
& 24 \text { - hall effect sensor; }
\end{aligned}
$$

\section{Experimental data and results}

Fig. 2 illustrates an excerpt of the results obtained from the experiments. The variation of the air-fuel ratio as a function of the brake power is shown for different load modes at a crankshaft rotation speed of $4500 \mathrm{~min}^{-1}$. The figure shown represents only part of the results of the research conducted at only one crankshaft rotation speed. According to results in Fig. 2 , the optimal values of air-fuel ratio are determined for a given crankshaft rotation speed. The 3D-view of the determined values of air-fuel ratios for all regimes of operation of engine are shown in the next figure. 


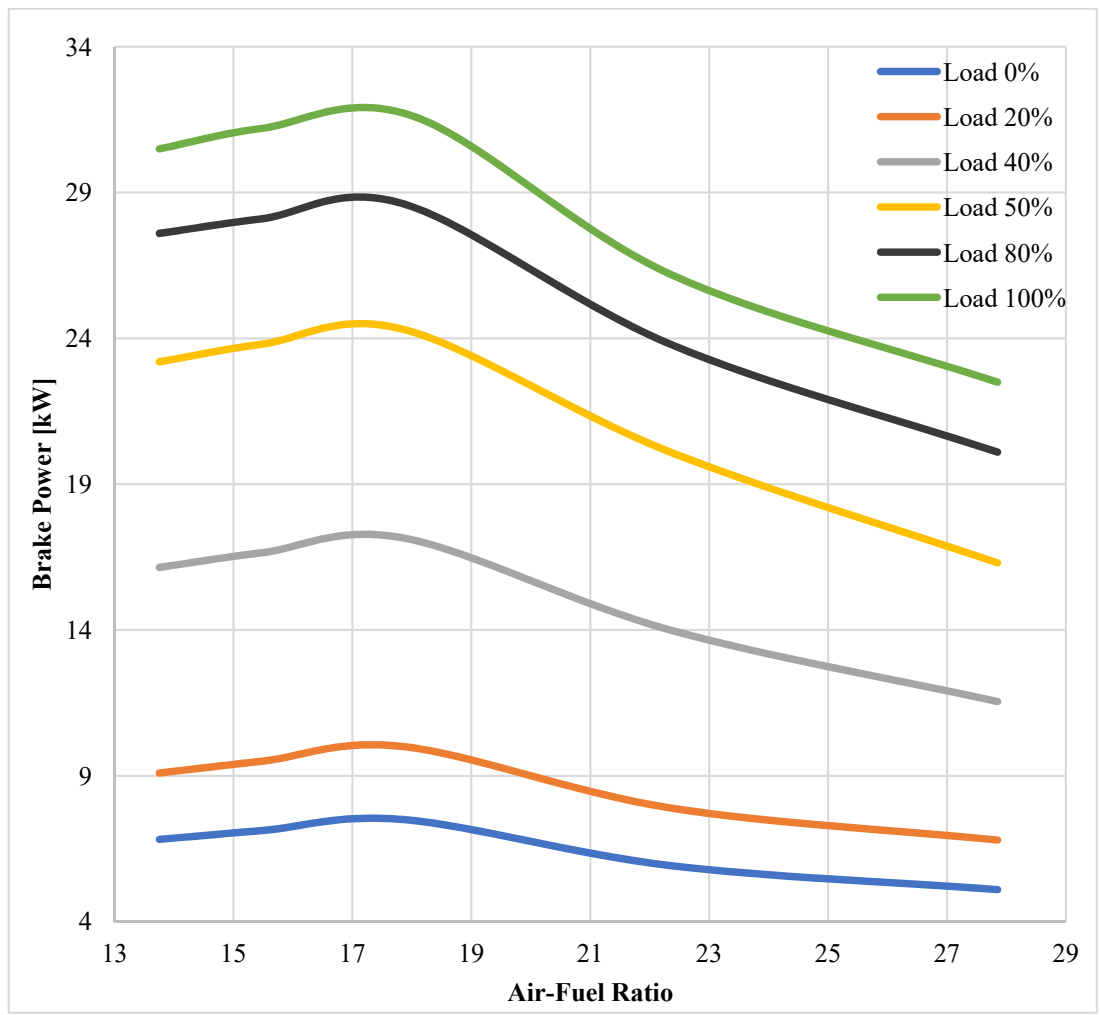

Fig. 2. Variation of Air-fuel ratio in function of Brake Power at a crankshaft rotation speed of 4500 $\min ^{-1}$.

The adjustment characteristics obtained refer to the entire load range (from a closed throttling valve, i.e. zero load to a fully open throttling valve, i.e. full load) at crankshaft rotation speeds of $1000 \mathrm{~min}^{-1}, 2000 \mathrm{~min}^{-1}$, $3000 \mathrm{~min}^{-1}, 3500 \mathrm{~min}^{-1}, 4500 \mathrm{~min}^{-1}$, $5500 \mathrm{~min}^{-1}$, and $6000 \mathrm{~min}^{-1}$.

The experimental results for the variation of the air-fuel ratio are shown in table 2.

Table 2. Experimental results.

\begin{tabular}{|c|c|c|c|c|c|c|}
\hline \multirow{2}{*}{$\begin{array}{c}\text { Crankshaft } \\
\text { rotation speed } \\
{[1 / \text { min] }}\end{array}$} & \multicolumn{7}{|c|}{$\%$ Opening throttle valve } \\
\cline { 2 - 7 } & $\mathbf{0}$ & $\mathbf{2 0}$ & $\mathbf{4 0}$ & $\mathbf{5 0}$ & $\mathbf{8 0}$ & $\mathbf{1 0 0}$ \\
\hline $\mathbf{1 0 0 0}$ & 15.13 & 15.30 & 15.13 & 15.30 & 15.30 & 15.30 \\
\hline $\mathbf{2 0 0 0}$ & 15.13 & 15.47 & 15.13 & 14.96 & 15.47 & 14.96 \\
\hline $\mathbf{3 0 0 0}$ & 16.33 & 15.47 & 15.81 & 14.96 & 15.13 & 15.81 \\
\hline
\end{tabular}




\begin{tabular}{|l|c|c|c|c|c|c|}
\hline $\mathbf{3 5 0 0}$ & 17.02 & 17.19 & 17.36 & 17.53 & 17.36 & 16.85 \\
\hline $\mathbf{4 5 0 0}$ & 17.53 & 17.88 & 18.05 & 17.88 & 17.88 & 18.05 \\
\hline $\mathbf{5 5 0 0}$ & 17.02 & 18.05 & 18.22 & 17.53 & 17.88 & 18.05 \\
\hline $\mathbf{6 0 0 0}$ & 16.85 & 18.05 & 17.88 & 18.39 & 18.57 & 17.96 \\
\hline
\end{tabular}

In order to be able to determine whether the mixture is rich or lean, it is necessary to convert the values shown in table 2 into equivalence air-fuel ratio $-\alpha$ (alfa) using the following equation:

$$
\alpha=\frac{A F R_{\text {actual }}}{A F R_{\text {ideal }}}
$$

where: $\mathrm{AFR}_{\text {actual }}$ are values from table $2, \mathrm{AFR}_{\text {ideal }}$ is 17.19 .

If the equivalence air-fuel ratio is less than 1 , the mixture is rich, and respectively, if the equivalence air-fuel ratio exceeds 1 , the mixture is lean. If the equivalence air-fuel ratio is equal to 1 , the mixture is stoichiometric.

To provide a clearer visualization, the data obtained are illustrated as a $3 \mathrm{D}$ diagram in Fig. 3.

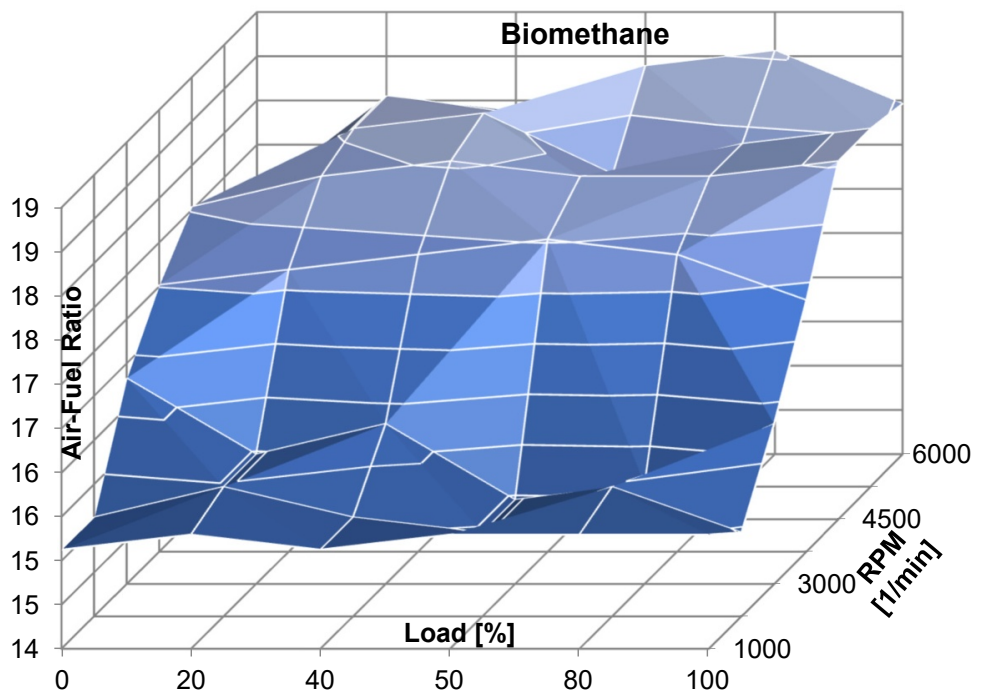

Fig. 3. 3D graph of results.

The figure shows the variation of optimal Air-Fuel ratio for all regimes of engine operation, depending on the variation of engine load and rotation speed over the whole 
operating range of the engine. By presenting the graph in $3 \mathrm{D}$ format, it is possible to understand the results of the experiment more clearly and to analyze the experiment results.

\section{Conclusions}

1. The highest efficiency of the engine requires an air-fuel ratio of approximately 15.3 at crankshaft rotation speeds or reach mixture for crankshaft rotation speed up to $2000 \mathrm{~min}^{-1}$.

2. For crankshaft rotation speeds up to the nominal crankshaft rotation speed, the air-fuel ratio is to be equal to or little more than 17.19 , corresponding to the stoichiometric mixture.

3. The change of air-fuel ratio of the mixture depends mainly on the crankshaft rotation speed rather than on the engine load.

4. The determination of the optimal air-fuel ratio of an engine running on biogas allows the engine to operate with maximum efficiency and minimized concentrations of harmful emissions in the exhaust gases.

\section{References}

1. EC, General and regional statistics (Eurostat Database, 2020)

2. EC, In focus: Renewable energy in Europe, Energy (Brussels, 2020)

3. IRENA, Global Renewables Outlook:Energy transformation 2050 (2020)

4. A. A. Yontar, Y. Dogu, Int. J. Engine Res., 21 (2020)

5. J. Heywood, Internal Combustion Engine Fundamentals (McGraw Hill, 1988)

6. J. Brodny, M. Tutak, P. Bindzár, Energies, 14, 3765 (2021)

7. S. Iliev, Processes, 9, 1322 (2021)

8. G. A. Sorin, E.Anca, Energy, 147 (2020)

9. L. Sitnik, Z. J. Sroka, M. K. Andrych-Zalewska, Energies, 14, 41 (2021)

10. E. Sosnina, A. Shalukho, L.Veselov, Proc. of UralCon, art. no.9216233 (2020)

11. D. Y. Damara, M. D. Dermawan, Proc. of ICT-PEP, 9249898 (2020)

12. M. Mouftahi, N. Tlili, N. Hidouri et al., Processes, 9, 48 (2021)

13. J. S. Byun, J. Park, J. Natural Gas Sci. Eng., 22 (2015)

14. E. Porpatham, A. Rameshand, B. Nagalingam, Fuel, 87 (8-9) (2008)

15. K. Biernat, I. Samson-Brek, Z. Chłopek, M. Owczuk, Energies, 14, 3356 (2021)

16. N. O'Connell, A. Röll, R. Lechner, T. Luo, M. Brautsch, Ren. Ener., 143 (2019)

17. S. Lee, U.H. Yi, H. Jang, C. Park, C. Kim, Energy, 220, 119766 (2021) 